\title{
A pre- and post-operative study of forty-six cases of slipped intervertebral disc
}

\author{
G. HARTO-GAROFALIDIS \\ M.D. \\ N. Papavassiliou \\ M.D.
}

CH. Rigopoulos
M.D.

B. T. Papathanassiou

M.D.

\section{Orthopaedic Department, University of Athens}

\section{Summary}

The results of operation on 46 cases of slipped disc have been studied.

The age of the patient and the duration of pre-operative symptoms both influence the late results.

Results were not usually satisfactory in cases with severe limitation of straight-leg raising.

Severe pressure on the nerve-root produces permanent changes and symptoms do not always disappear after its relief.

The presence of degenerative changes, visible on the radiograph, is associated with poor late results.

Tears of the posterior longitudinal ligament are associated with satisfactory late results.

In the majority of cases, the early and late results were similar.

\section{Introduction}

In the period $1957-66,470$ patients with a proved lesion of the intervertebral disc were admitted to the Orthopaedic Department of the University of Athens. Seventy-seven (16.3\%) of these patients underwent surgery.

This figure, in our opinion, does not represent the true percentage of patients needing surgery, which should be smaller, between $5-10 \%$, but it must be noted that our patients had usually been treated conservatively already, elsewhere, or were neglected cases unable to undergo a long course of conservative treatment.

Forty-six out of these seventy-seven cases form the basis of this study, as it has only been possible to collect pre- and post-operative data from this number.

All operations were performed by the same group of surgeons, with the same basic technique. It has been possible, therefore, to assess the final results with considerable precision.

\section{Material and methods}

Our series consists of thirty-four male and twelve female patients, the higher incidence in the male sex being due to heavy occupational activities. Twenty-five out of the thirty-four male patients were farmers or labourers.

Thirty-one patients were below 40 years of age. Only four older than 50 were operated on.

The main symptoms in all patients were lowback pain and sciatica. Forty-two of them presented with both symptoms, twenty suffered from low-back pain and sciatica simultaneously, twenty had low-back pain first, followed by sciatica, and only two presented with sciatica and later developed low-back pain.

In this study the following clinical, radiological and operative data were collated:

The duration of the pre-operative symptoms. The age of the patient.

The clinical signs.

Radiological findings-particularly the presence or absence of wedge-shaped narrowing of the intervertebral space and of degenerative changes.

Operative findings-particularly the presence of a tear in the posterior longitudinal ligament and of a true protrusion of the nucleus pulposus.

The pathology of the removed intervertebral disc.

As late results we considered those maintained for at least 6 months after operation. They were classed as follows:

1. Excellent. The patients were symptom-free and had returned to their previous occupations within 4 months.

2. Good. The patients had slight symptoms but were working within 4 months.

3. Fair. The patients complained of symptoms severe enough to warrant rest from work. 
4. Poor. The patients complained of the same symptoms as they had prior to the operation. Some were slightly improved but could not return to work.

Thirty-nine patients were followed up for a period of time from 6 months to 8 years after surgery. Late results are missing for seven patients (Table 1).

TABLE 1

Length of follow-up of thirty-nine operated cases

\begin{tabular}{lc}
\hline Follow-up & No. of cases \\
\hline 6-12 months & 14 \\
1-3 years & 13 \\
3-5 years & 3 \\
$5-8$ years & 9 \\
Total & 39 \\
\hline
\end{tabular}

\section{Indications for surgery}

An absolute indication for immediate operation is the presence of motor disturbance, i.e. foot-drop.

Another indication is the presence of symptoms showing no response to $1 \frac{1}{2}-2$ months of conservative treatment.

In some cases the indication was not one of the above. This happened in neglected cases with long-standing symptoms or those having a short history but doing heavy manual work (labourers, farm-hands).

\section{Duration of pre-operative symptoms}

Better results were obtained with patients who had symptoms of recent onset (up to 6 months). This suggests that conservative treatment should not be continued beyond a certain period of time (Table 2).

TABLE 2

Duration of pre-operative symptoms and late results

\begin{tabular}{lccccc}
\hline \multirow{2}{*}{$\begin{array}{c}\text { Duration of } \\
\text { symptoms }\end{array}$} & No. of & \multicolumn{5}{c}{ Late results } \\
\cline { 3 - 6 } & cases & $\begin{array}{c}\text { Excellent } \\
\text { or good }\end{array}$ & Fair & Poor & $\begin{array}{c}\text { Miss- } \\
\text { ing }\end{array}$ \\
\hline Up to 6 months & 14 & 10 & 3 & 1 & - \\
6-12 months & 11 & 5 & 3 & 1 & 2 \\
12-24 months & 10 & 6 & 2 & - & 2 \\
Over 24 months & 11 & 5 & 2 & 1 & 3 \\
\hline
\end{tabular}

\section{The influence of age}

A relation was found between the patient's age and the late results, which were best in patients below 40 years of age: in thirty-three such cases we had twenty excellent and good results, five fair and three poor.

Late results are missing for five cases (Table 3).

TABLE 3

Relation of age to late results

\begin{tabular}{lcccccc}
\hline & & \multicolumn{5}{c}{ Late results } \\
\cline { 3 - 7 } Age group & No. of & $\begin{array}{c}\text { Excel- Good } \\
\text { lent }\end{array}$ & & Fair & Poor & $\begin{array}{c}\text { Miss- } \\
\text { ing }\end{array}$ \\
\hline 20-30 years & 15 & 4 & 3 & 4 & 1 & 3 \\
$31-40$ years & 18 & 5 & 8 & 1 & 2 & 2 \\
41-50 years & 9 & 1 & 4 & 3 & - & 1 \\
Over 50 years & 4 & 1 & - & 2 & - & 1 \\
\hline
\end{tabular}

\section{Clinical signs}

Special consideration was given to scoliosis which suggested an acute phase. Thirty-four out of forty-six patients presented with it and occasionally with a forward bending of the trunk as well.

Bending toward the pain-free side was observed in thirty out of thirty-four patients ; ipsilateral bending was noted in the remaining four.

Out of the thirty patients with contralateral bending seventeen were found to have a disc protrusion at the L4-L5 space and seven at L5-S1. (In each of the remaining six cases two discs were removed.)

In the four patients with bending to the side of the sciatica a protrusion was found at the L4-L5 space (two cases) and the L5-S1 (two cases).

The above facts suggest that the scoliosis (ipsior contra-lateral) is not related to the level of the disc protrusion but to the pararadical or paracaudal position of the protrusion (Armstrong, 1952).

Straight-leg raising was considered positive when limited to $45-50^{\circ}$. It was considered strongly positive when limited to $30^{\circ}$. The late results were usually unfavourable in the presence of a strongly positive sign. Out of thirteen cases with straight-leg raising up to $30^{\circ}$, no excellent results were obtained (Table 4).

TABLE 4

Relation of straight-leg raising to late results

\begin{tabular}{cccccccc}
\hline & & \multicolumn{5}{c}{ Final results } \\
\cline { 3 - 7 } SLR & $\begin{array}{c}\text { No. of } \\
\text { cases }\end{array}$ & $\begin{array}{l}\text { Excel- Good } \\
\text { lent }\end{array}$ & Fair & $\begin{array}{c}\text { Poor Miss- } \\
\text { ing }\end{array}$ \\
\hline $\begin{array}{c}\text { Up to } 30^{\circ} \\
\begin{array}{c}\text { Over } 30^{\circ} \text { or } \\
\text { negative }\end{array}\end{array}$ & 13 & - & 3 & 6 & 1 & 3 \\
\hline
\end{tabular}




\section{Radiological findings}

The wedge-shaped narrowing of the intervertebral space, especially of L4-L5, when in accordance with the clinical diagnosis, helps to determine the level of the protrusion. Such a narrowing was observed in fifteen of our forty-six cases always at the L4-L5 space. In two of those cases where the clinical picture indicated pressure on the S1 root, a protrusion was actually found at operation at the L5-S1 space.

The presence of degenerative changes had an unfavourable influence upon the late results. Such changes were observed in seven cases (excellent 0 , good 2 , fair 4 , poor 1 ). Sacralization (five cases) and spina bifida (two cases) did not influence the late results and are not, we believe, an indication for spinal fusion.

In sacralization of the L5 vertebra symptoms arising from the S1 root may be observed, and the slipped disc may be found at the L4-L5 space (two cases).

Myelography was very rarely performed. It is considered important only in cases where the diagnosis is doubtful. We performed only three myelograms in our series.

\section{Operative findings}

From our total of forty-six cases, in twentyone the disc from the L4-L5 space was removed, in twelve the disc from the L5-S1 space, in eleven both discs from the L4-L5 and L5-S1 spaces, and in one case the disc from the L3-L4 space was removed.

In one case the disc was not removed on account of excessive bleeding; the early postoperative results were excellent, however, and the late results, 16 months after surgery, good. Apparently the removal of the ligamentum flavum alone produced adequate decompression of the nerve-root.

Spinal fusion was performed in addition to disc removal in three cases.

The findings at operation fell into two main groups: one in which there was a tear of the posterior longitudinal ligament with disc-material in the spinal canal and another in which the posterior longitudinal ligament was intact.

1. A tear of the posterior longitudinal ligament was found in seven cases. This could not be correlated with the patient's age, the duration of symptoms or the cause of the initial attack (Table 5). However, the results were uniformly satisfactory: four were classed excellent and three good.

2. Protrusion of the disc without tear of the posterior longitudinal ligament was recorded in thirteen cases. In five we had excellent, in four good, in four fair, and one poor late results. (For one case the results are missing.)

TABLE 5

The age of the patient, the duration of symptoms and the cause of initial attack in the group found to have a torn posterior longitudinal ligament

\begin{tabular}{ccll}
\hline Case No. & Age & Duration & \multicolumn{1}{c}{ Cause } \\
\hline 1 & 46 & 2 months & No injury \\
2 & 34 & 2 years & No injury \\
3 & 22 & 2 years & Fall from height \\
4 & 30 & 3 months & No injury \\
5 & 37 & 3 months & No injury \\
6 & 32 & 2 months & Jump \\
7 & 32 & 1 year & No injury \\
\hline
\end{tabular}

\section{Post-operative course}

A normal post-operative course was observed in twenty-seven cases. A slight fever was recorded in twelve cases, up to $38-38 \cdot 2^{\circ} \mathrm{C}$, during the early post-operative period, without any relevant clinical or laboratory signs of infection.

An actual infection developed in one case.

The recorded post-operative complications are summarized in Table 6.

TABLE 6

Post-operative complications

\begin{tabular}{ll}
\hline Local infection & 1 \\
Genito-urinary infection & 1 \\
Respiratory infection & 2 \\
Post-operative ileus & 1 \\
Herpes zoster & 1 \\
Thrombophlebitis & 1 \\
\hline
\end{tabular}

\section{Pathological changes}

The changes which the disc undergoes with age, consist of dehydration of the nucleus pulposus and of the annulus fibrosus. Furthermore the nucleus pulposus undergoes myxomatous degeneration and the annulus fibrosus a hyaloid degeneration. Simultaneously, mainly on the annulus fibrosus, a concretion of calcium salts occurs. In the presence of inflammation, even an aseptic one, a leucocytic infiltration is noted. This infiltration takes place mainly in the annulus fibrosus, as the avascular nucleus produces no inflammatory response.

Twenty-seven out of forty-six discs removed were examined microscopically. In eleven of them an infiltration of leucocytes was found to be present, and in sixteen the discs were found to be normal. No relation was found between the structure of the removed discs, the various factors studied in this paper (age, duration of pre- 
operative symptoms, clinical signs, etc.) and the late results of the operation.

\section{Early and late results}

As early results we considered those achieved during the first post-operative days, by the time of the patient's discharge, as late results those maintained for at least 6 months after the operation (Tables 7 and 8).

TABLE 7

Early post-operative results

\begin{tabular}{cl}
\hline No. of cases & Early results \\
\hline 10 & Excellent \\
19 & Good \\
12 & Fair \\
5 & Poor \\
\hline
\end{tabular}

TABLE 8

Late post-operative results

\begin{tabular}{cl}
\hline No. of cases & Late results \\
\hline 11 & Excellent \\
13 & Good \\
10 & Fair \\
3 & Poor \\
7 & Missing \\
\hline
\end{tabular}

The comparison of early and late results is of interest. The excellent or good early results in twenty-one of twenty-nine cases were maintained ; two deteriorated and were ranked at their last examination as fair and poor. Late results are missing for five cases.
Out of twelve cases with fair early results five improved and were, at a later stage, considered good or excellent, six remained fair and for the remaining case late results are missing.

The five cases with poor results at the early rating either remained poor (two cases) or improved slightly enough to be ranked fair (two cases) (Table 9).

TABLE 9

Comparison of early and late results

\begin{tabular}{clc}
\hline \multicolumn{1}{c}{ Early results } & \multicolumn{2}{c}{ Late results } \\
\hline $\begin{array}{c}\text { Excellent or good } \\
\text { (29 cases) }\end{array}$ & Excellent or good & 21 cases \\
& Fair & 2 cases \\
& Poor & 1 case \\
Fair & Missing & 5 cases \\
(12 cases) & Excellent or good & 5 cases \\
& Fair & 6 cases \\
Poor & Poor & 0 \\
$(5$ cases $)$ & Missing & 1 case \\
& Excellent or good & 0 \\
& Fair & 2 cases \\
& Poor & 2 cases \\
& Missing & 1 case \\
\hline
\end{tabular}

\section{References}

ARMSTrong, J.R. (1952) Lumbar Disc Lesions, p. 60. Livingstone, Edinburgh.

Friberg, S. \& HIRSCH, G. (1964) On late results of operative treatment for intervertebral disc prolapses in the lumbar region. Acta chir. scand. 93, 161.

HiRSCH, C. \& NACHEMSON, A. (1963) The reliability of lumbar disc surgery. Clin. Orthop. 29, 189.

Rolander, S. (1963) Technical problems in lumbar fusion. In Proceedings of the Scandinavian Orthopaedic Association. Acta orthop. scand. 33, 362.

UNANDER-SCHARIN, L. (1948) The results of lumbar fusion in disc degeneration. Acta orthop. scand. 18, 125. 